\title{
Protective strategies among patients with cardiovascular diseases against dust phenomenon exposure in Ahvaz city based on the protection motivation theory
}

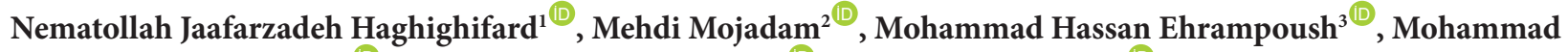

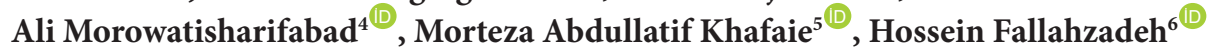 \\ ${ }^{1}$ Toxicology Research Center, Ahvaz Jundishapur University of Medical Sciences, Ahvaz, Iran \\ ${ }^{2}$ Department of Health in Emergency and Disaster, School of Public Health, Shahid Sadoughi University of Medical Sciences, Yazd, Iran \\ ${ }^{3}$ Environmental Science and Technology Research Center, Department of Environmental Health Engineering, School of Public Health, \\ Shahid Sadoughi University of Medical Sciences, Yazd, Iran \\ ${ }^{4}$ Department of Aging and Health, School of Public Health, Shahid Sadoughi University of Medical sciences, Yazd, Iran \\ ${ }^{5}$ Environmental Technologies Research Center, Social Determinants of Health Research Center, Ahvaz Jundishapur University of \\ Medical Sciences, Ahvaz, Iran \\ ${ }^{6}$ Department of Biostatistics and Epidemiology, School of Public Health, Shahid Sadoughi University of Medical Sciences, Yazd, Iran
}

\begin{abstract}
Background: Dust particles are one of the most important environmental problems that are threatening many countries, and patients with cardiovascular diseases (CVDs) are a vulnerable group in this respect. The present study was conducted to examine the protective strategies among patients with CVDs against exposure to dust phenomenon based on the protection motivation theory (PMT).

Methods: This cross-sectional study was performed on 183 patients with CVDs who referred to health care centers in Ahvaz city, Khuzestan province, southwest of Iran. Participants were selected from patients with CVDs recruited for routine national Package of Essential Non-communicable Disease (IRA-PEN) through random cluster sampling. Data were collected using a researcher-made questionnaire based on the PMT. Data were analyzed using descriptive and analytical tests such as Pearson correlation coefficient and multiple linear regressions by SPSS version 22 .

Results: The mean scores of the constructs of perceived response efficacy $(4.06 \pm 20.06)$ and sensitivity $(19.89 \pm 4.30)$ were higher than those of other constructs. Correlation coefficient test showed a significant positive correlation between risk behaviors of exposure to dust phenomenon and self-efficacy, response efficacy and protection motivation, but negatively correlated with cost response. Also, self-efficacy variable, type of health insurance, and protection motivation were the predictive indicators of behavior. Conclusion: The constructs of the PMT explained the risk reduction behaviors of exposure to dust phenomenon in patients with CVDs. Therefore, this theory can be used as a framework for designing educational programs to increase the motivation of patients with CVDs to adopt risk reduction behaviors for exposure to dust.

Keywords: Dust, Risk reduction behavior, Motivation, Self-efficacy, Iran

Citation: Jaafarzadeh Haghighifard N, Mojadam M, Ehrampoush MH, Morowatisharifabad MA, Abdullatif Khafaie M, Fallahzadeh H. Protective strategies among patients with cardiovascular diseases against dust phenomenon exposure in Ahvaz city based on the protection motivation theory. Environmental Health Engineering and Management Journal 2021; 8(1): 1-8. doi: 10.34172/ EHEM.2021.01.
\end{abstract}

\author{
Article History: \\ Received: 4 August 2020 \\ Accepted: 20 November 2020 \\ ePublished: 19 February 2021
}

*Correspondence to:

Mehdi Mojadam,

Email: mehdi.8984@yahoo.com

\section{Introduction}

Iran, as one of the main countries in the Middle East and southwest of Asia, is frequently exposed to local and regional dust phenomena and dust systems in the arid and semi-arid belt (1). Dust is a mass of solid particles and smoke that is distributed in the atmosphere and restricts horizontal visibility (2). According to the World Meteorological Organization, a dust storm is a wind that is specific to arid and semi-arid areas, and as a result, a cloud of dust is created in space which makes visibility difficult (3).

One of the most important environmental problems that threatens many developing countries today is air pollution mainly due to dust particles $(4,5)$. Researchers have shown that the sources of dusty storms in arid and semi-arid regions include Sahara, the Middle East, Southeast Asia, 
and Mongolia. Also, Northwest of the United States and Australia are known as other sources of dust (6). Iran neighboring to a large part of deserts and facing to stream dust phenomenon over the past several years. Ahvaz, the capital of Khuzestan province, which is located in the southwest Iran, is the city most affected by dust event days (7). In this regard, at the onset of a dust event, referral of patients to the medical care system increases by $70 \%$ in this city. The burden due to unhealthy atmosphere, school, airports, and offices closures is estimated to be more than one billion dollars per year (8).

Most airborne particles have a size ranging from 0.1 to 10 micrometers (8) and almost $40 \%$ of all particles which have a size of 1 to 2 microns remain in the bronchi and air sacs (9). Increased suspended particles can have a significant relationship with increased risk of cardiovascular diseases (CVDs). In fact, the effects of CVDs caused by air pollution account for $30 \%$ of deaths around the world. These effects also lead to higher financial costs, reduced quality of life (10), clinical symptoms in vulnerable people such as children, the elderly, and pregnant women, and increasing the number of patients with CVDs $(11,12)$.

Although several studies have been conducted on air pollution in general, and dust in particular $(1-3,5-8,10,11)$, few studies have been conducted using educational theories, including studying the knowledge, attitude, and protective behaviors of teachers against dust phenomenon using the Health Belief Model (13), such as the studying of drivers' knowledge of dust (14).

Theories provide valuable tools for understanding and solving a wide range of behavioral problems. There are numerous theories of health behavior in the literature, each of which tries to explain why people behave or fail to behave. Health behavior theories are very important for understanding behaviors and interventions aimed at increasing health behaviors (15). Some studies suggest that interventions should have a motivational component (16). For example, the protection motivation theory (PMT), introduced by Rogers, has been widely accepted as a framework for prediction and intervention in healthrelated behaviors (17). Based on this theory, threat assessment evaluates maladaptive behaviors and includes rewards for inaccurate behaviors and perceived threats (severity and vulnerability). Receiving rewards from improper behaviors increases the probability of choosing maladaptive responses, while perceived threats reduce maladaptive choices $(18,19)$. This means that based on the PMT, patients with CVDs are likely to avoid exposure to dust knowing they are more susceptible (perceived sensitivity) and its harm is serious (perceived severity) and also, not adhering to protective behavior will not rewards them more.

Assessment of coping is the ability to repatriate the threat and deal with the threat. Enhancing the assessment of coping increases the incentive to protect, and thus, increase the probability of behavior and includes perceived response efficacy, perceived self-efficacy, and perceived response costs. The perceived response efficacy is the expectation of person that the adaptive response can eliminate the perceived threat; and is expected to increase the effectiveness of suggested responses of preventive behaviors (20). The self-efficacy of a person is the belief in being able to perform well-behaved adaptive behaviors and recommended behaviors. It is expected that an understanding of high self-efficacy will lead to more positive responses in the individuals $(20,21)$. Response costs include total Barriers in recommending preventive behaviors, including financial and non-financial costs, such as time, effort, discomfort, and etc. Increased cost of applying health behaviors reduces motivation for behaviors (21). The assessment of coping is obtained with the sum of the response efficacy and the perceived selfefficacy minus the response cost. In this way, an increase in the response efficacy and self-efficacy and a reduction in the response cost will increase the assessment of coping, therefore, response efficacy and self-efficacy increase the ability to select adaptive responses, while the reaction of the response cost reduces the choice of adaptive responses (20). The efficacy of the two mediation processes creates the protection motivation and behavior (22). In order to be motivate protective attitude, perceived severity and perceived sensitivity must overcome incompatible response rewards, and also perceived self-efficacy and perceived response efficacy must overcome consistent response costs. Protection motivation is an intermediate variable between the stages of threat assessment, assessment of coping and preventive behavior (20). Therefore, considering the vulnerability of patients with CVDs to the risks of dust exposure and limited the same researches, the present study aimed to examine protective strategies of patients with CVDs against exposure to dust phenomenon based on the PMT.

\section{Materials and Methods}

This cross-sectional study was performed on 183 patients with CVDs who referred to the health care centers in Ahvaz from September to October 2018 (Figure 1). The patients had a history of myocardial infarction, cardiac stent, open heart surgery, or heart bypass, and were identified through the CVD screening program (routine national Package of Essential Non-communicable Disease (IRAPEN)). They were at least 30 years of age and experienced more than one exposure to dusts in Ahvaz during the past year. Participants were selected through random cluster sampling. At first, out of 23 urban health centers in Ahvaz, 10 were randomly selected as cluster. Then, from the files of patients with CVDs in the integrated health information system record (Sib), 10 clusters, and the proportion of the population which covered a number of cases were selected using random number generator program.

The context of study, confidentiality of information, and the purpose of this study were explained to 


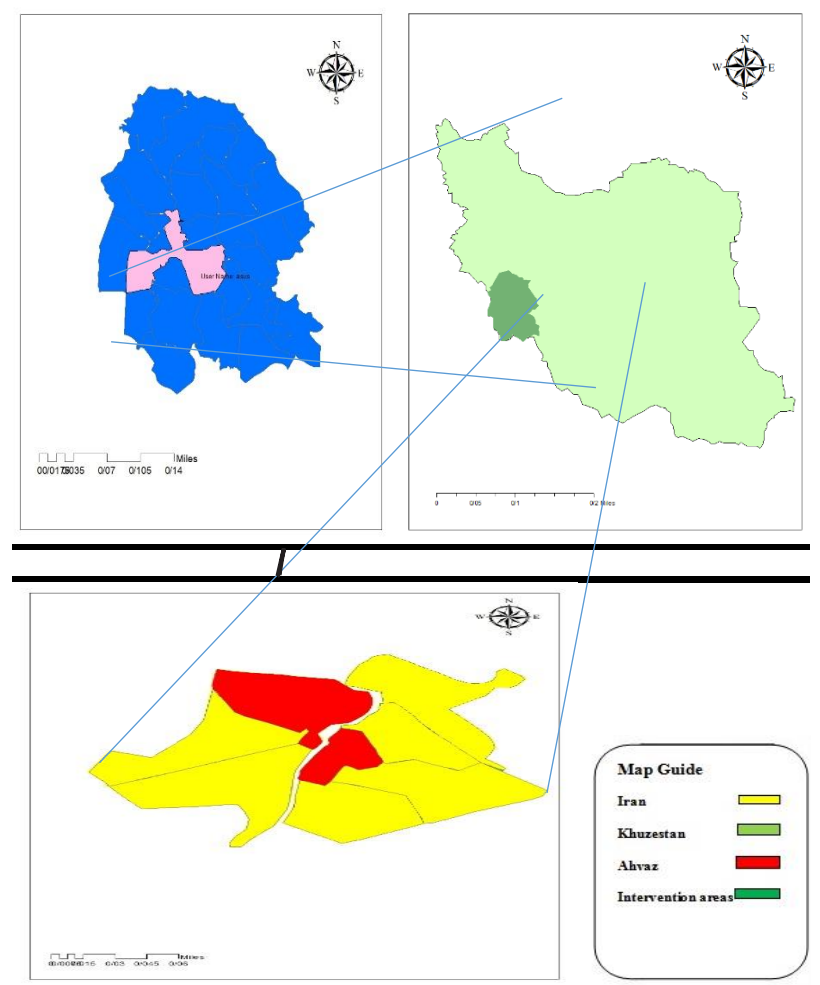

Figure 1. Map of Ahvaz city in Khuzestan province, southwest of Iran.

the participants. After giving informed consent, all participants were willing to participate in the study. Then, the questionnaire was completed by the subjects. The data were collected using a researcher-made questionnaire based on the PMT which is consisted of three parts. The first part was related to demographic characteristics such as age, gender, employment status, educational status, number of households, etc. The second part was related to the constructs of PMT including perceived sensitivity (5 questions, score range $=5-25$ ), perceived severity (6 questions, score range $=6-30)$, perceived reward $(4$ questions, score range $=4-20$ ), perceived fear (6 questions, score range $=6-30$ ), perceived self-efficacy ( 5 questions, score range $=5-25)$, perceived response efficacy (5 questions, score range $=5-25)$, perceived response costs (5 questions, score range $=5-25)$, and protection motivation (4 questions, score range $=4-20$ ). The third part included 6 questions related to behavior with scores ranging from 6 to 30. The questions of the researchermade questionnaire were prepared based on the codes, categories, and subcategories obtained from a previous qualitative study (23). The reliability of the questionnaire was evaluated through qualitative content validity and the content was distributed to 15 faculty members in health education, environmental health, and health in disaster in Ahvaz, Yazd, and Tehran Universities of Medical Sciences, and their comments were applied. Then, the quantitative content validity was evaluated and confirmed using the content validity ratio $(\mathrm{CVR})=0.65$ and content validity index $(\mathrm{CVI})=0.84$. Cronbach's alpha method was used to measure the reliability of the questionnaire. For this purpose, a questionnaire was given to 25 patients with CVDs who were not included in the study. The Cronbach's alpha values obtained for the nine constructs of the questionnaire are as follows: Perceived sensitivity $(0.822)$, perceived severity (0.889), perceived reward (0.923), perceived fear (0.890), perceived self-efficacy (0.677), perceived response efficacy (0.881), perceived response cost $(0.917)$, protection motivation $(0.810)$, and behavior (0.744).

Data were analyzed using descriptive statistics (mean and standard deviation) and analytical statistics (Pearson's correlation coefficient and multiple linear regression) by SPSS version 20. Statistical significant level was considered at $P=0.05$.

\section{Results}

Participants in this study were 104 men and 79 women. The mean age of the participants was $49.22 \pm 13.83$ years, ranged from 30 to 84 years. Of all participants, $77.6 \%$ were married and $39.3 \%$ of them had university education. Also, $32.8 \%$ were employed and $30.6 \%$ were housewives; and most participants (59\%) lived with their children (Table 1).

Table 1. Frequency distribution of demographic characteristics of research samples

\begin{tabular}{|c|c|c|c|}
\hline Variables & Grouping variables & Frequency & Percent \\
\hline \multirow{2}{*}{ Sex } & Male & 104 & 56.8 \\
\hline & Female & 79 & 43.2 \\
\hline \multirow{4}{*}{ Marital status } & Single & 22 & 12 \\
\hline & Married & 142 & 77.6 \\
\hline & Divorced & 3 & 1.6 \\
\hline & Widow & 16 & 8.7 \\
\hline \multirow{5}{*}{ Educational status } & Illiterate & 15 & 8.2 \\
\hline & Elementary & 27 & 14.8 \\
\hline & Middle school & 31 & 16.9 \\
\hline & High school & 38 & 20.8 \\
\hline & Academic & 72 & 39.3 \\
\hline \multirow{5}{*}{ Employment status } & Housewife & 56 & 30.6 \\
\hline & Employed & 60 & 32.8 \\
\hline & Retired & 27 & 14.8 \\
\hline & Unemployed & 12 & 6.6 \\
\hline & Self-employed & 28 & 15.3 \\
\hline \multirow{5}{*}{ Residence status } & With wife & 31 & 16.9 \\
\hline & With his wife and children & 108 & 59 \\
\hline & With children & 17 & 9.3 \\
\hline & Alone & 11 & 6 \\
\hline & With parents & 16 & 8.7 \\
\hline \multirow{2}{*}{$\begin{array}{l}\text { Health insurance } \\
\text { coverage }\end{array}$} & Yes & 158 & 86.3 \\
\hline & No & 25 & 13.7 \\
\hline
\end{tabular}


The mean scores of participants, based on the PMT constructs are shown in Table 2. The perceived response efficacy was $20.06 \pm 4.06$ and the perceived sensitivity was $19.89 \pm 4.30$, which were higher than the other constructs.

Pearson correlation coefficient test showed a significant positive correlation between risk reduction behaviors of dust exposure in CVDs patients and perceived self-

Table 2. Mean, standard deviation, score ranges in the field of the protection motivation theory and risk reduction behaviors of dust exposure in patients with CVDs

\begin{tabular}{lccc}
\hline \multicolumn{1}{c}{ Constructs } & Mean \pm SD & $\begin{array}{c}\text { Possible } \\
\text { range }\end{array}$ & $\begin{array}{c}\text { Mean } \\
\text { percentage of } \\
\text { maximum }\end{array}$ \\
\hline Perceived sensitivity & $18.89 \pm 4.30$ & $9-25$ & 79.56 \\
\hline Perceived severity & $22.40 \pm 5.16$ & $6-30$ & 74.66 \\
\hline Perceived reward & $11.39 \pm 4.17$ & $4-20$ & 56.95 \\
\hline Perceived fear & $22.21 \pm 4.94$ & $6-30$ & 74.03 \\
\hline Perceived self-efficacy & $17.79 \pm 4.45$ & $5-25$ & 71.16 \\
\hline perceived response & $20.06 \pm 4.06$ & $5-25$ & 80.24 \\
efficacy & $16.58 \pm 4.95$ & $5-25$ & 66.32 \\
\hline perceived response cost & $15.10 \pm 3.23$ & $4-20$ & 75.5 \\
\hline Protection motivation & $13.62 \pm 2.75$ & $6-18$ & 75.66 \\
\hline Behavior & & & \\
\hline
\end{tabular}

efficacy $(P<0.001, \mathrm{r}=0.389)$, response efficacy $(P<0.001$, $\mathrm{r}=0.286)$ and protection motivation $(P=0.007, \mathrm{r}=0.199)$; and there was a significant negative correlation with a perceived response cost $(P=0.005, \mathrm{r}=-0.209)$ (Table 3$)$.

In the first phase of regression analysis, in order to predict behavior using theoretical constructs, it was revealed that protection motivation $(P=0.001)$ and selfefficacy $(P=0.003)$ had the most predictive behavior. In total, theoretical constructs predicted behavioral changes of $27 \%\left(R^{2}=0.270\right)$. In the second phase of regression analysis, using all the variables, self-efficacy $(P=0.002)$, protection motivation $(\mathrm{P}=0.016)$, and type of health insurance coverage $(P=0.005)$ had the most predictive behaviors; these variables predicted behavioral changes in a total of $33.5 \%\left(\mathrm{R}^{2}=0.335\right)$ (Table 4$)$.

The most important sources that increased people's information include health workers giving information to 74 people $(40.3 \%)$, radio and television giving information to 55 people (30\%), web giving information to 33 people $(28 \%)$, and doctors giving information to 24 people (13.1\%).

\section{Discussion}

This study aimed to investigate the risk reduction behaviors of dust exposure in patients with CVDs based

Table 3. Correlation coefficient matrix of the protection motivation theory constructs and risk reduction behaviors of dust exposure in patients with CVDs

\begin{tabular}{|c|c|c|c|c|c|c|c|c|c|}
\hline Constructs & $\begin{array}{l}\text { Perceived } \\
\text { sensitivity }\end{array}$ & $\begin{array}{c}\text { Perceived } \\
\text { severity }\end{array}$ & $\begin{array}{l}\text { Perceived } \\
\text { reward }\end{array}$ & $\begin{array}{l}\text { Perceived } \\
\text { fear }\end{array}$ & $\begin{array}{c}\text { Perceived } \\
\text { self-efficacy }\end{array}$ & $\begin{array}{c}\text { Perceived } \\
\text { response } \\
\text { efficacy }\end{array}$ & $\begin{array}{c}\text { Perceived } \\
\text { response } \\
\text { cost }\end{array}$ & $\begin{array}{l}\text { Protection } \\
\text { motivation }\end{array}$ & Behavior \\
\hline Perceived sensitivity & 1 & & & & & & & & \\
\hline Perceived severity & ${ }^{*} 0.572$ & 1 & & & & & & & \\
\hline Perceived reward & ${ }^{* *} 0.216$ & ${ }^{* *} 0.379$ & 1 & & & & & & \\
\hline Perceived fear & 0.514 & "*0.516 & ${ }^{*} 0.236$ & 1 & & & & & \\
\hline Perceived self-efficacy & 0.069 & 0.073 & ${ }^{*} 0.219$ & 0.089 & 1 & & & & \\
\hline $\begin{array}{l}\text { Perceived response } \\
\text { efficacy }\end{array}$ & ${ }^{* *} 0.221$ & 0.132 & 0.062 & "*0.301 & "*0.559 & 1 & & & \\
\hline Perceived response cost & ${ }^{*} 0.224$ & ${ }^{*} 0.406$ & ${ }^{* *} 0.261$ & 0.420 & $0.033-$ & ${ }^{*} 0.161$ & 1 & & \\
\hline Protection motivation & ${ }^{* *} 0.258$ & ${ }^{* *} 0.228$ & 0.030 & 0.437 & ${ }^{* *} 0.234$ & ${ }^{* *} 0.394$ & ${ }^{* *} 0.390$ & 1 & \\
\hline Behavior & $0.001-$ & $0.101-$ & $0.009-$ & $0.120-$ & ${ }^{* *} 0.389$ & ${ }^{* *} 0.286$ & *0.209- & ${ }^{* *} 0.199$ & 1 \\
\hline
\end{tabular}

${ }^{*}$ Correlation is significant at $\mathrm{P}=0.01$ (2-tailed).

${ }^{*}$ Correlation is significant at $\mathrm{P}=0.05$ (2-tailed).

Table 4. Regression model in predicting the risk reduction behavior of dust exposure in patients with CVDs

\begin{tabular}{|c|c|c|c|c|c|}
\hline \multirow{2}{*}{ Variables } & \multicolumn{2}{|c|}{ Unstandardized coefficients } & \multirow{2}{*}{$\begin{array}{c}\text { Standardized coefficients } \\
\text { Beta }\end{array}$} & \multirow{2}{*}{$\mathbf{t}$} & \multirow{2}{*}{$P$ value } \\
\hline & B & Std. Error & & & \\
\hline (Constant) & 11.744 & 2.194 & & 5.352 & 0.000 \\
\hline Perceived self-efficacy & 0.156 & 0.051 & 0.254 & 3.076 & 0.002 \\
\hline Perceived response efficacy & 0.121 & 0.060 & 0.179 & 2.025 & 0.044 \\
\hline Perceived response cost & -0.124 & 0.045 & -0.224 & -2.785 & 0.006 \\
\hline Protection motivation & 0.170 & 0.070 & 0.200 & 2.428 & 0.016 \\
\hline Medical insurance coverage status & 1.588 & 0.561 & 0.199 & 2.830 & 0.005 \\
\hline
\end{tabular}

$\mathrm{R}^{2}=0.335$ 
on the PMT. It was revealed that risk reduction behaviors of $75.66 \%$ for dust exposure in patients with CVDs were reported to be good, which is not consistent with the results reported by Ramezankhani et al, who estimated that the protective behavior against dust to be medium, and only a few teachers in their study used standard masks during dusty days (13). Also, in a descriptive study by Praphant study, the preventive behavior against dust and relating factors among the workers in the lime factories and stone crushing mills in Nakhon Si Thammarat province, Thailand, was investigated, and it was revealed that at least half of the participants showed preventive behaviors (24). The enhancement of the participants' information in the present study compared with previous studies could be attributed to the risk of CVDs, and the increase of training due to the severity and frequency of dust events in Ahvaz.

The perceived sensitivity of patients with CVDs regarding risk reduction behaviors of dust exposure was good, indicating that patients with CVDs are susceptible to dust and are at a high risk, and when these patients accept their sensitivity to dust, they will adopt risk reduction behaviors against the dust phenomenon. The results of studies by Ramezankhani et al and Praphant indicated that most of the participants considered themselves vulnerable to dust $(13,24)$ and this high sensitivity can lead to protective behavior in the dusty days. Rahimi et al reported a significant correlation between perceived sensitivity and protection motivation. This means that the higher the score of a person's perception of their vulnerability to the risk of noise-induced hearing loss, the higher the protection motivation score (25), which is consistent with the results of other studies $(26,27)$. Therefore, in order to promote protection motivation, it is necessary to work on increasing people's perception of their vulnerability.

Also, the CVD patients' perceived severity about the risk of dust exposure was good. In the study of Ramezankhani et al, most teachers believed that dust particles were hazardous, which was a positive factor in protecting behaviors (13). In the study of Praphant, the perceived severity of teachers about dust based on the degree of disability and mortality, was moderate (24). Regarding the importance of determining the effects of dust exposure, it is possible to increase the perceived severity in patients with CVDs, in terms of attitude; they are prepared to take risk reduction behaviors to dust exposure. Also, Rahimi et al showed that most of the women participating in the study had a good understanding of the severity of the consequences of home accidents, and mentioned the injury-related costs as one of the most serious risks associated with home accidents (25).

Spence et al showed that people's risk perception of the dust phenomenon has a positive effect on their incompatibility with this phenomenon. Here, risk perception shows how people study and understand climate change. When people have a bad experience of climate change and remember that experience, based on the psychological pressure on the individual, this affects how people perceive the risks of climate change. For example, people affected by floods and hurricanes are much more concerned about climate change than those who have not experienced the risk, and are more likely to think about adaptive behavior (26).

In response to perceived rewards, the results indicated that patients with CVDs received moderate rewards for inappropriate behavior; and nearly half of the people commitment to the job, doing routine tasks, fewer nuisances to those around them, and avoiding argue with family as a reason for not adopting risk reduction behaviors for dust exposure. The amount of this construct was moderate in the study of Babazadeh et al, which focused on skin cancer prevention behaviors (28).

Perceived fear of dangers of dust exposure and its subsequent problems in this study were estimated to be high, which is consistent with the results of studies by Sharifirad et al, on the fear of influenza (29), and Baghianimoghadam et al, on the skin cancer preventive behaviors (30). This may indicate that the occurrence of dust-related complications will make patients with CVDs to adopt better preventive behaviors at the next dust exposure.

In the present study, perceived self-efficacy was good, indicating that individuals were assured of their ability to perform recommended behaviors at the desired level, which is consistent with the results reported by Ramezankhani et al (13). However, in the study of Babazadeh et al, perceived self-efficacy of farmers towards skin cancer indicated the low level of farmers' beliefs that they could adopt protective behaviors to prevent skin cancer (28). Considering that self-efficacy is an important factor in determining the intention of healthy behaviors and self-care behaviors $(31,32)$, it is necessary to emphasize on this construct, and develop and implement more effective training programs.

The results of the present study showed that the perceived response efficacy of patients with CVDs to the risk of dust exposure was good, which indicates their proper awareness of the benefits of the risk reduction behaviors to dust exposure. This finding is not consistent with the results of studies by Baghianimoghadam et al and Babazadeh et al, which reported a low response efficacy $(30,33)$. The difference is more likely to be due to the different target group and problem.

The perceived response cost by the patients was estimated to be moderate, and showed that many patients with CVDs do not tend to use risk reduction behaviors for dust exposure for a variety of reasons. The most common reasons for not using masks in this study were unpleasant feelings and choking, which is consistent with the results of study by Shams and Shamsi (34). Also, Morowatisharifabad et al showed that a few subjects used masks, which indicates their reluctance to protect 
themselves against health hazards (35). This reluctance has also been reported in the study of Melamed et al on protective devices (36). In a study by Qian et al, half of the participants reported that they did not use masks when leaving home and going outdoors (37). Stay home and being in leave will affect their income. Also constructing modification of building like using double glass windows is costly. There were also other common reasons for the perceived response cost (37). The results show that, the more perceived barriers lead to less protection motivation behavior.

The findings showed that the protection motivation construct was good, which is consistent with the results of a study by Abbasi-Shavazi et al who investigated the predictors of using respiratory protection masks among workers of sanitary ware companies. Their results showed a very good intention of workers to use masks, so that they wanted to use the mask for 22 of the next 30 days. In other words, they were ready to use the mask (38). However, in the study of Raymond and Lusk, few workers were prepared to use a protective mask (39). In the present study, all the PMT constructs, except perceived rewards, had a significant correlation with the motivation protection construct. In the study of Baghianimoghadam et al, all the theoretical constructs showed a strong correlation with the intention construct (31). Also, the study of Kaviani et al, showed that the motivation protection against skin cancer was significantly correlated with the theoretical constructs (40). In this study, there was no significant correlation between perceived rewards and protection motivation (40). The above-mentioned results suggest that the increase in perceived rewards, possibly accompanied by unhealthy behavior, may reduce the incentive to protect those behaviors.

Risk reduction behaviors against exposure to dust, along with perceived self-efficacy and perceived response efficacy and protection motivation showed a significant positive correlation. In the study of Sharifirad et al, perceived sensitivity, perceived response, efficacy, and perceived self-efficacy showed a significant correlation with behavior (29). Also, the study of Baghianimoghadam et al showed that skin cancer preventive behaviors had a positive correlation with perceived sensitivity, perceived severity, perceived self-efficacy, and perceived response efficacy (41). This correlation showed that those who believed that protective behaviors could be effective in reducing the risk of dust exposure, and those who were able to behave in reducing the risk of dust exposure, showed higher protection motivation and did the right behavior.

The perceived response cost construct showed a significant negative correlation with behavior. This result is consistent with the results of studies by Weinstein and Morowatisharifabad et al, which showed that the perceived response cost was reduced by motivation and negative correlation behavior $(42,35)$. This result shows that, the more conducive the perceived barriers to protective behavior, the less the individual's motivation for protective behavior. The most important perceived barriers in this study were unpleasant feeling and choking when using masks, failure to receive or reduce the salary, and possibility of dismissal from work, if staying at home, and suffering high financial costs if needed to use an air purifier.

Regression analysis showed that perceived self-efficacy, protection motivation, perceived response efficacy, perceived response cost constructs, and type of health insurance coverage variables significantly predicted preventive behavior. In the study of Kaviani et al, in terms of preventive behaviors of skin cancer, perceived severity, perceived fear, perceived efficacy, and protection motivation significantly predicted preventive behavior (40). Therefore, stakeholders in the field of health are recommended to provide all their interventions based on the PMT, and emphasize the above-mentioned constructs to provide more effective education.

The present study showed that most patients with CVDs received their information through health center staff, which is not consistent with the results of studies by Ramezankhani et al and Qian et al, in which the patients received their information through radio and television or television and the Internet $(13,37)$.

\section{Conclusion}

This study confirms the effectiveness of the PMT in identifying the determinants of risk reduction behaviors in patients with CVDs. Therefore, this theory can be emphasized with perceived self-efficacy, perceived response efficacy, and perceived response cost as a framework for designing educational programs in order to increase the cardiovascular protection motivation and to adopt risk reduction behaviors for exposure to dust.

\section{Acknowledgements}

This research is a part of Ph.D. thesis in Health in Disasters and Emergencies at Shahid Sadoughi University of Medical Sciences, Yazd, Iran. The authors would like to thank all people who contributed to the implementation of this research.

\section{Ethical issues}

The protocols of this study were reviewed and approved by the Ethics Committee of Shahid Sadoughi University of Medical Sciences, Yazd, Iran (Ethical code: IR.SSU. SPH.REC.1396.36). The authors hereby certify that all data collected during the research are as expressed in the manuscript, and no data from the study has been or will be published elsewhere separately.

\section{Competing interests}

The authors declare that they have no conflict of interests. 


\section{Authors' contributions}

All authors have contributed in the study design, data collection and analysis, and manuscript preparation. The final version of this manuscript was reviewed and confirmed by all authors.

\section{References}

1. Rasouli A, Saraf B, Mohammadi GH. The evaluation of dust climatic phenomenon occurrence trend current years 55 in the west part of Iran by nonparametric statistical methods. Phys Geog Res 2010; 9: 15-28. [In Persian].

2. Miller SD, Kuciauskas AP, Liu M, Ji Q, Reid JS, Breed DW, et al. Haboob dust storms of the southern Arabian Peninsula. J Geophys Res Atmos 2008; 113(D1):1-26. doi: 10.1029/2007jd008550.

3. Wang S, Yuan W, Shang K. The impacts of different kinds of dust events on PM10 pollution in northern China. Atmos Environ 2006; 40(40): 7975-82. doi: 10.1016/j. atmosenv.2006.06.058.

4. Trivedy RK, Goel PK. An Introduction to Air Pollution. Jaipur, India: ABD Publishers; 2010.

5. Al-Hurban AE, Al-Ostad AN. Textural characteristics of dust fallout and potential effect on public health in Kuwait city and suburbs. Environ Earth Sci 2010; 60(1): 169-81. doi: 10.1007/s12665-009-0177-3.

6. Hong Y. A nation wide meeting summary of discussing sand-dust storm weathers occurred in China. Journal of Gansu Meteorology 1993; 11(3): 6-11.

7. Zarasvandi A, Moore F, Nazarpour A. Mineralogy and morphology of dust storms particles in Khuzestan province: XRD and SEM analysis concerning. Iranian Journal of Crystallography and Mineralogy 2011; 19(3): 511-8. [In Persian].

8. Shahsavani A, Yarahmadi M, Jafarzade Haghighifard N, Naimabadie A, Mahmoudian MH, Saki H, et al. Dust storms: environmental and health impacts. Journal of North Khorasan University of Medical Sciences 2011; 2(4): 45-56. doi: 10.29252/jnkums.2.4.45. [In Persian].

9. Griffin DW. Atmospheric movement of microorganisms in clouds of desert dust and implications for human health. Clin Microbiol Rev 2007; 20(3): 459-77. doi: 10.1128/ cmr.00039-06.

10. Mohamadi S, Kaviannejad R. Crisis of Air Pollution and Cardiovascular Disease. 8th International Congress on Health in Emergencies and Disasters; 2017 Apr 22-24; Tehran.

11. Bennion P, Hubbard R, O'Hara S, Wiggs G, Wegerdt J, Lewis $S$, et al. The impact of airborne dust on respiratory health in children living in the Aral Sea region. Int J Epidemiol 2007; 36(5): 1103-10. doi: 10.1093/ije/dym 195.

12. Department of Ecology State of Washington. Air Quality Program. USA: Department of Ecology State of Washington; 2014.

13. Ramezankhani A, Doostifar K, Moteseddi Zarandi S, Marashi T, Shakeri N, Reisi M. Evaluation of knowledge, attitude and protective behaviors of teachers against dust phenomenon based on the health belief model. Journal of Health System Research 2014; 9(14): 1735-45. [In Persian].

14. Albushokeh SA, Bakhtiarpour S, Jafarzadeh Haghighi Fard N, Ahangari A. Comparison knowledge of drivers in about dust, and damage the health and economic problems caused by dust varies according to the type of car drivers. First National Conference on Geography, Environmental Hazards Sustainable Development; 2013 Mar 3; Ahvaz, Islamic Azad Universityof Ahvaz.

15. Noar SM. A health educator's guide to theories of health behavior. Int Q Community Health Educ 2005-2006; 24(1): 75-92. doi: 10.2190/dalp-3f95-gct3-m922.

16. Prentice-Dunn S, Floyd DL, Flournoy JM. Effects of persuasive message order on coping with breast cancer information. Health Educ Res 2001; 16(1): 81-4. doi: 10.1093/her/16.1.81.

17. Rogers RW. A protection motivation theory of fear appeals and attitude change1. J Psychol 1975; 91(1): 93-114. doi: 10.1080/00223980.1975.9915803.

18. Donna LF, Steven PD, Ronald WR. A meta-analysis of research on protection motivation theory. Journal of Applied Social Psychology 2000; 30(2): 407-29. doi: 10.1111/j.1559-1816.2000.tb02323.x.

19. Wu Y, Stanton BF, Li X, Galbraith J, Cole ML. Protection motivation theory and adolescent drug trafficking: relationship between health motivation and longitudinal risk involvement. J Pediatr Psychol 2005; 30(2): 127-37. doi: 10.1093/jpepsy/jsi001.

20. Mojadam M, Ehrampoush MH, Jaafarzadeh Haghighifard N, Abdullatif Khafaie M, Fallahzadeh H, Morowatisharifabad MA. Dust phenomenon: threat appraisal of cardiovascular patients. Journal of Disaster and Emergency Research 2020; 3(2): 87-96. doi: 10.18502/jder.4031

21. Cismaru M. Using protection motivation theory to increase the persuasiveness of public service communications. SIPP Public Policy Pap. Feb2006.

22. Norman P, Boer H, Seydel ER. Protection motivation theory. In: Conner M, Norman P. Predicting Health Behaviour: Research and Practice with Social Cognition Models. Maidenhead: Open University Press; 2005. p. 81126.

23. Mojaddam M. Design, implementation and evaluation of effect of interventional programs dust phenomenon exposure risk reduction in ahvaz cardiovascular disease patients based on the protection motivation theory: a mix method approach. Yazd: Shahid Sadoughi University of Medical Sciences; 2019.

24. Praphant A. Preventive behaviors form dust among workers in lime factories and stone crushing mills, Nakhon Si Thammarat Province [dissertation]. Bangkok: College of Public Helath; 2003.

25. Rahimi T, Faryabi R, Javadi A, Shojaei S. Attitudes of women from Jiroft city about prevention of home injuries in children under 5 years using protection motivation theory in 2015. Journal of Rafsanjan University of Medical Sciences 2017; 16(1): 17-30. [In Persian].

26. Spence A, Poortinga W, Butler C, Pidgeon NF. Perceptions of climate change and willingness to save energy related to flood experience. Nat Clim Chang 2011; 1(1): 46-9. doi: 10.1038/nclimate 1059 .

27. Arabtali B, Solhi M, Shojaeezadeh D, Gohari M. Related factors in using Hhearing protection device based on the Protection motivation theory in Shoga factory workers, 2011. Iran Occupational Health 2015; 12(1): 1-11. [In Persian]. 
28. Babazadeh T, Tazval J, Moradijoo M, Moradi F, Mirzaeian $\mathrm{K}$. Threat appraisal of skin cancer in farmers of Chaldoran county, 2014-2015. Community Health Journal 2016;10(1):40-51. [In Persian].

29. Sharifirad G, Yarmohammadi P, Morowatisharifabad MA, Rahayi Z. The status of preventive behaviors regarding influenza (A) H1N1 pandemic based on protection motivation theory among female high school students in Isfahan, Iran. Health System Research 2011; 7(1): 108-17. [In Persian].

30. Baghianimoghadam MH, Mohammadi S, Norbala MT, Mazloomi SS. The study of factors relevant to skin cancer preventive behavior in female high school students in Yazd based on protection motivation theory. Knowledge and Health 2010; 5(1): 10-5. [In Persian].

31. Huang HT, Kuo YM, Wang SR, Wang CF, Tsai CH. Structural factors affecting health examination behavioral intention. Int J Environ Res Public Health 2016; 13(4): 395. doi: 10.3390/ijerph13040395.

32. Kaiser B, Razurel C, Jeannot E. Impact of health beliefs, social support and self-efficacy on physical activity and dietary habits during the post-partum period after gestational diabetes mellitus: study protocol. BMC Pregnancy Childbirth 2013; 13: 133. doi: 10.1186/14712393-13-133.

33. Babazadeh T, Tazval J, Moradi F, Safaralizadeh F, Mahmoodi $\mathrm{H}$. Coping with skin cancer in farmers of rural areas of Chalderan county. Journal of Health in the Field 2016; 3(4): 32-40. [In Persian].

34. Shams M, Shamsi M. Increasing the usage of personal protective equipments in constructing subway stations: an application of social marketing model. Armaghane Danesh 2013; 18(6): 495-508. [In Persian].

35. Melamed S, Rabinowitz S, Feiner M, Weisberg E, Ribak J. Usefulness of the protection motivation theory in explaining hearing protection device use among male industrial workers. Health Psychol 1996; 15(3): 209-15. doi: 10.1037//0278-6133.15.3.209.

36. Qian X, Xu G, Li L, Shen Y, He T, Liang Y, et al. Knowledge and perceptions of air pollution in Ningbo, China. BMC Public Health 2016; 16(1): 1138. doi: 10.1186/s12889-0163788-0.

37. Abbasi-Shavazi M, Baghianimoghadam $\mathrm{MH}$, Rezaeipandari H, Chaleshgar M, Morowatisharifabad MA. Predictors of using respiratory protection masks among workers of sanitary ware companies in Yazd, Iran, based on the theory of planned behavior. Journal of Mazandaran University of Medical Sciences 2017; 27(151): 180-92. [In Persian].

38. Raymond DM 3rd, Lusk SL. Staging workers' use of hearing protection devices: application of the transtheoretical model. AAOHN J 2006; 54(4): 165-72. doi: 10.1177/216507990605400406.

39. Kaviani A, Roozbahani N, Khorsandi M. The assessment of the protection motivation theory construct of skin cancer preventive behaviors in rural women. Avicenna Journal of Nursing and Midwifery Care 2016; 24(4): 229-37. doi: 10.21859/nmj-24043. [In Persian].

40. Baghianimoghadam MH, Mohammadi S, Mazloomi Mahmoudabad SS, Norbala MT. The effect of education based on protection-motivation theory on skin cancer preventive practices among female high school students in Yazd. The Horizon of Medical Sciences 2011; 17(1): 27-34. [In Persian].

41. Weinstein ND. Testing four competing theories of healthprotective behavior. Health Psychol 1993; 12(4): 324-33. doi: 10.1037//0278-6133.12.4.324.

42. Morowatisharifabad MA, Hadi Varnamkhavasti L, Zare M, Fallahzadeh H, Karimiankakolaki Z. Study of determinants of lung cancer protective behaviors in Esfahan steel company workers based on protection motivation theory. Tolooebehdasht 2017; 16(3): 67-80. [In Persian]. 